\title{
Lung cancer in never-smoker Asian females is driven by oncogenic mutations, most often involving EGFR
}

\author{
Sang Yun $\mathrm{Ha}^{1, *}$, So-Jung Choi ${ }^{2, *}$, Jong Ho $\mathrm{Cho}^{3, *}$, Hye Joo Choi ${ }^{2}$, Jinseon Lee ${ }^{2}$, \\ Kyungsoo Jung ${ }^{4}$, Darry Irwin ${ }^{5}$, Xiao Liu' ${ }^{6,7}$, Maruja E. Lira8, Mao Mao9, Hong Kwan \\ $\mathrm{Kim}^{3}$, Yong Soo Choi ${ }^{3}$, Young Mog Shim ${ }^{3}$, Woong Yang Park ${ }^{10}$, Yoon-La Choi ${ }^{1,4,10}$, \\ Jhingook Kim ${ }^{2,3}$ \\ ${ }^{1}$ Department of Pathology and Translational Genomics, Samsung Medical Center, Sungkyunkwan University School of \\ Medicine, Seoul, Korea \\ ${ }^{2}$ Samsung Biomedical Research Institute, Samsung Medical Center, Sungkyunkwan University School of Medicine, Seoul, \\ Korea \\ ${ }^{3}$ Department of Thoracic and Cardiovascular Surgery, Samsung Medical Center, Samsung Biomedical Research Institute, \\ Sungkyunkwan University School of Medicine, Seoul, Korea \\ ${ }^{4}$ Samsung Advanced Institute for Health Sciences \& Technology, Sungkyunkwan University School of Medicine, Seoul, Korea \\ ${ }^{5}$ Agena Bioscience, Sequenom, San Diego, CA, USA \\ ${ }^{6}$ BGI-Shenzhen, Shenzhen, 518083, China \\ ${ }^{7}$ Department of Biology, University of Copenhagen, Copenhagen, Denmark \\ ${ }^{8}$ Oncoloy Research Unit, Pfizer Worldwide Research and Development, San Diego, CA, USA \\ ${ }^{9}$ WuXi AppTec, Shanghai, China \\ ${ }^{10}$ Samsung Genome Institute, Samsung Medical Center, Sungkyunkwan University School of Medicine, Seoul, Korea \\ *These authors contributed equally to this work \\ Correspondence to: \\ Jhingook Kim, e-mail: jhingookkim@gmail.com \\ Yoon-La Choi, e-mail: ylachoi@skku.edu \\ Keywords: non-small cell lung cancer, adenocarcinoma, never-smoker female, driver mutation, EGFR \\ Received: August 07, 2014 \\ Accepted: December 16, 2014 \\ Published: February 28, 2015
}

\section{ABSTRACT}

The aim of this study was to determine the distribution of known oncogenic driver mutations in female never-smoker Asian patients with lung adenocarcinoma. We analyzed 214 mutations across 26 lung cancer-associated genes and three fusion genes using the MassARRAY ${ }^{\circledR}$ LungCarta Panel and the ALK, ROS1, and RET fusion assays in 198 consecutively resected lung adenocarcinomas from never-smoker females at a single institution. EGFR mutation, which was the most frequent driver gene mutation, was detected in $124(63 \%)$ cases. Mutation of ALK, KRAS, PIK3CA, ERBB2, BRAF, ROS1, and RET genesoccurred in 7\%, 4\%, 2.5\%, 1.5\%, 1\%, 1\%, and $1 \%$ of cases, respectively. Thus, $79 \%$ of lung adenocarcinomas from never-smoker females harbored well-known oncogenic mutations. Mucinous adenocarcinomas tended to have a lower frequency of known driver gene mutations than other histologic subtypes. EGFR mutation was associated with older age and a predominantly acinar pattern, while ALK rearrangement was associated with younger age and a predominantly solid pattern. Lung cancer in never-smoker Asian females is a distinct entity, with the majority of these cancers developing from oncogenic mutations.

\section{INTRODUCTION}

Lung cancer is the leading cause of cancer-related mortality, with 1.38 million annual deaths worldwide [1]. Tobacco smoking is the main risk factor for lung cancer; however, approximately $25 \%$ of lung cancers worldwide occur in never-smokers [2, 3]. Moreover, the risk of lung cancer differs by race/ethnicity. In the United States, approximately $10 \%$ of patients with lung cancer are never-smokers [4], while in Asia, $>30 \%$ of 
patients with lung cancer are never-smokers and $\geq 50 \%$ of lung cancers occur in women who are never-smokers [5]. Never-smoker East Asian females have a tendency to develop adenocarcinoma, and these never-smokers exhibit higher treatment response rates to epidermal growth factor receptor tyrosine kinase inhibitors (EGFR-TKIs), such as gefitinib and erlotinib, than those with a history of tobacco smoking [6]. In several phase III studies, significantly better response rates and longer progression-free survival were observed in advanced non-small cell lung cancer (NSCLC) patients harboring activating EGFR mutations who were treated with first-line EGFR-TKIs than those patients treated with doublet platinum-based chemotherapy $[7,8]$. In addition, a fusion protein of the N-terminal portion of the echinoderm microtubule-associated protein-like $4(E M L 4)$ gene and the intracellular signaling portion of the anaplastic lymphoma kinase (ALK) tyrosine kinase receptor has been identified in a small subset of NSCLC patients [9]. Patients harboring the EML4-ALK fusion show unique clinicopathologic and physiological characteristics and respond positively to $A L K$ inhibitors [10-12]. As for $E G F R$ mutations, several reports have identified the $E M L 4-A L K$ fusion protein predominantly in young female never-smokers with adenocarcinoma, although the presence of this fusion protein is mutually exclusive with EGFR mutation [9, 13]. More specifically, the EML4-ALK fusion gene was found in $23.7 \%$ of neversmoker female lung adenocarcinoma patients [14].

Lung adenocarcinoma in never-smoker females has been established as a distinct entity based on its particular epidemiologic, clinical, and biological characteristics. EGFR mutations and the EML4-ALK translocation are defined as driver mutations because these alterations are responsible for both initiation and maintenance of lung cancer. The discovery of driver oncogene genetic variants that are sensitive to molecular-targeted drugs is crucial for improvement of treatment strategies. Therefore, use of multi-mutational profiling in lung cancer studies is important for identification of driver gene alterations in order to validate the effectiveness of molecular-targeted therapies. In addition, the proportion of never-smokers with lung cancer is likely to increase as a result of smoking cessation and prevention programs. Thus, the aims of this study were to analyze the distribution of oncogenic driver mutations and to compare these mutations with clinicopathologic characteristics in female Asian neversmoker lung adenocarcinoma patients.

\section{RESULTS}

\section{Patient population and histopathologic classification}

The patient population is summarized in Table 1. All patients were women with no smoking history. Median age at diagnosis was 60 years (range, 29-81 years). Most patients $(85.3 \%)$ had undergone lobectomy. Two patients had pleural metastasis at the time of surgery. Eleven (5.6\%) patients had received neoadjuvant concurrent chemoradiation therapy. Among the 198 patients in this study, $104(52.5 \%)$ patients had T1 stage tumors, 83 (41.9\%) patients had T2 stage tumors, and 11 (5.6\%) patients had T3 stage tumors. Nine patients did not undergo lymph node dissection and were excluded from the analysis of $\mathrm{N}$ stage. N0, N1, and N2 stage tumors were observed in $124(65.6 \%), 25(13.2 \%)$, and $40(21.2 \%)$ patients, respectively. Two of the 198 cases were classified as minimally invasive adenocarcinomas with an invasive component of $<5 \mathrm{~mm}$. Invasive adenocarcinomas were classified as predominantly acinar (142 cases, 71.7\%), predominantly papillary (18 cases, $9.1 \%$ ), predominantly solid (17 cases, 8.6\%), predominantly lepidic (9 cases, $4.5 \%$ ), and predominantly micropapillary (1 case, $0.5 \%)$ patterns. Nine $(4.5 \%)$ cases were classified as mucinous adenocarcinoma. Two minimally invasive adenocarcinomas were classified as predominantly lepidic for statistical analysis. In addition, all histologic patterns that were observed in $>10 \%$ of the tumor area were recorded. An acinar pattern was observed in 169 (85.4\%) cases. Papillary, lepidic, micropapillary, solid, and mucinous patterns were observed in 68 (34.3\%), 36 (18.2\%), $36(18.2 \%), 33(16.7 \%)$, and 17 (8.6\%) cases, respectively.

\section{Fusion gene and LungCarta analyses}

The results of the fusion gene and LungCarta analyses are summarized in Figure 2 and Table 2, and a full list of mutations that were identified is shown in Supplemental Table 1. Among the 198 cases, driver mutations were detected in 157 (79\%) cases. EGFR mutations were the most frequently found mutation in lung adenocarcinomas of female never-smokers (124 cases, 63\%). EGFR mutations were detected in exon 19 in $47(24 \%)$ cases, exon 20 in $16(8 \%)$ cases, exon 21 in $58(29 \%)$ cases, exons 18 and 21 in 2 (1\%) cases, and exons 18 and 20 in $1(1 \%)$ case. $A L K$ rearrangement was observed in $14(7 \%)$ of cases. The frequencies of KRAS, PIK3CA, TP53, ERBB2, and BRAF mutations were $4 \%, 2.5 \%, 2 \%, 1.5 \%$, and $1 \%$, respectively. $R O S 1$ and $R E T$ gene rearrangements were each found in 2 (1\%) cases. ALK, ROS1, and RET gene fusions were mutually exclusive with EGFR and KRAS mutations. The gene mutations were mutually exclusive with the exception of concurrent mutation of EGFR/PIK3CA $(n=3), E G F R / T P 53(n=1), A L K / T P 53(n=2)$, $K R A S / P I K 3 C A(n=1)$, and KRAS/ERBB2 $(n=1$; Figure 3$)$. The results of Sanger sequencing validation were consistent with the results of LungCarta analyses in all cases (Supplemental Table 2). 
Table 1: Patient population

\begin{tabular}{|c|c|}
\hline Characteristics & Number of patients $(\%)$ \\
\hline Age, years & median 60 (range, 29-81) \\
\hline \multicolumn{2}{|l|}{ Histologic classification } \\
\hline Minimally invasive adenocarcinoma & $2(1.0)$ \\
\hline \multicolumn{2}{|l|}{ Invasive adenocarcinoma } \\
\hline Lepidic predominant & $9(4.5)$ \\
\hline Acinar predominant & $142(71.7)$ \\
\hline Papillary predominant & $18(9.1)$ \\
\hline Micropapillary predominant & $1(0.5)$ \\
\hline Solid predominant & $17(8.6)$ \\
\hline Mucinous adenocarcinoma & $9(4.5)$ \\
\hline \multicolumn{2}{|l|}{ T stage } \\
\hline 1 & $104(52.5)$ \\
\hline 2 & $83(41.9)$ \\
\hline 3 & $11(5.6)$ \\
\hline \multicolumn{2}{|l|}{ N stage ${ }^{1}$} \\
\hline 0 & $124(65.6)$ \\
\hline 1 & $25(13.2)$ \\
\hline 2 & $40(21.2)$ \\
\hline \multicolumn{2}{|l|}{ M stage } \\
\hline 0 & $196(99.0)$ \\
\hline 1 & $2(1.0)$ \\
\hline \multicolumn{2}{|l|}{ Operation } \\
\hline Wedge resection & $16(8.0)$ \\
\hline Lobectomy & $169(85.3)$ \\
\hline Lobectomy $+\alpha^{2}$ & $13(6.6)$ \\
\hline \multicolumn{2}{|l|}{ Neoadjuvant CCRT ${ }^{3}$} \\
\hline Yes & $11(5.6)$ \\
\hline No & $187(94.4)$ \\
\hline
\end{tabular}

${ }^{1}$ Nine cases were excluded because lymph node dissection was not performed.

${ }^{2} \alpha$ includes lobectomy with wedge resection of the other lobe, bilobectomy, or pneumonectomy.

${ }^{3} \mathrm{CCRT}$ indicates concurrent chemoradiation therapy.

\section{Relationship between driver mutation status and clinicopathologic characteristics}

The relationship between the driver mutation status and histologic subclassification of adenocarcinoma is summarized in Table 2 and Figure 4A-4E. Tumors with EGFR mutation exhibited a high frequency of predominantly acinar patterns and an absence of a predominantly mucinous pattern. $A L K$ rearrangements were frequently found in cases with a predominantly solid pattern. KRAS mutations were detected with high frequency in cases with predominantly mucinous tumors. BRAF mutations were detected only in predominantly papillary tumors. These four genes were significantly associated with the histologic subclassification. Mucinous adenocarcinoma tended to harbor a lower frequency of known driver gene mutations than other histologic subtypes (mutation rate, $44.4 \%$ vs. $80.4 \%$; $p=0.090$ ). 


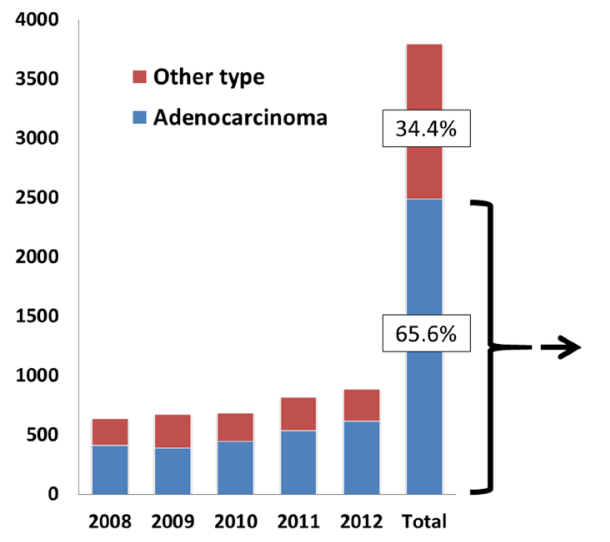

A

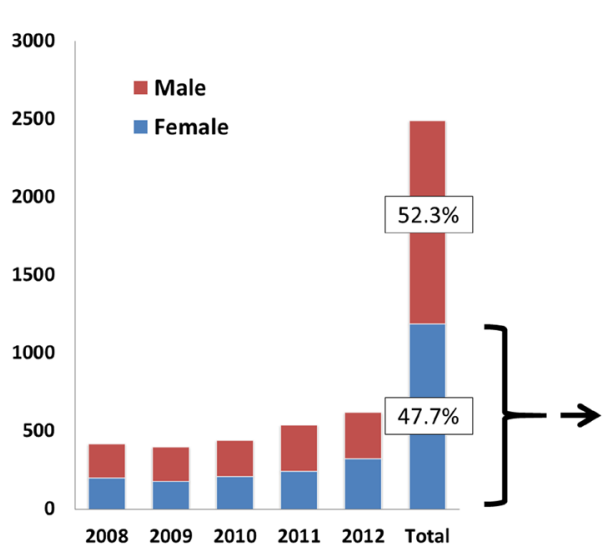

B



C

Figure 1: Process of patient (female never smoker with lung adenocarcinoma) selection in this study. (A) Distribution of lung cancer according to histology subtype. (B) Distribution of lung adenocarcinoma according to gender. (C) Distribution of lung adenocarcinoma from female according to smoking status. Patients with no medical record of smoking status were excluded. The record of year 2012 was not shown due to lack of smoking information.

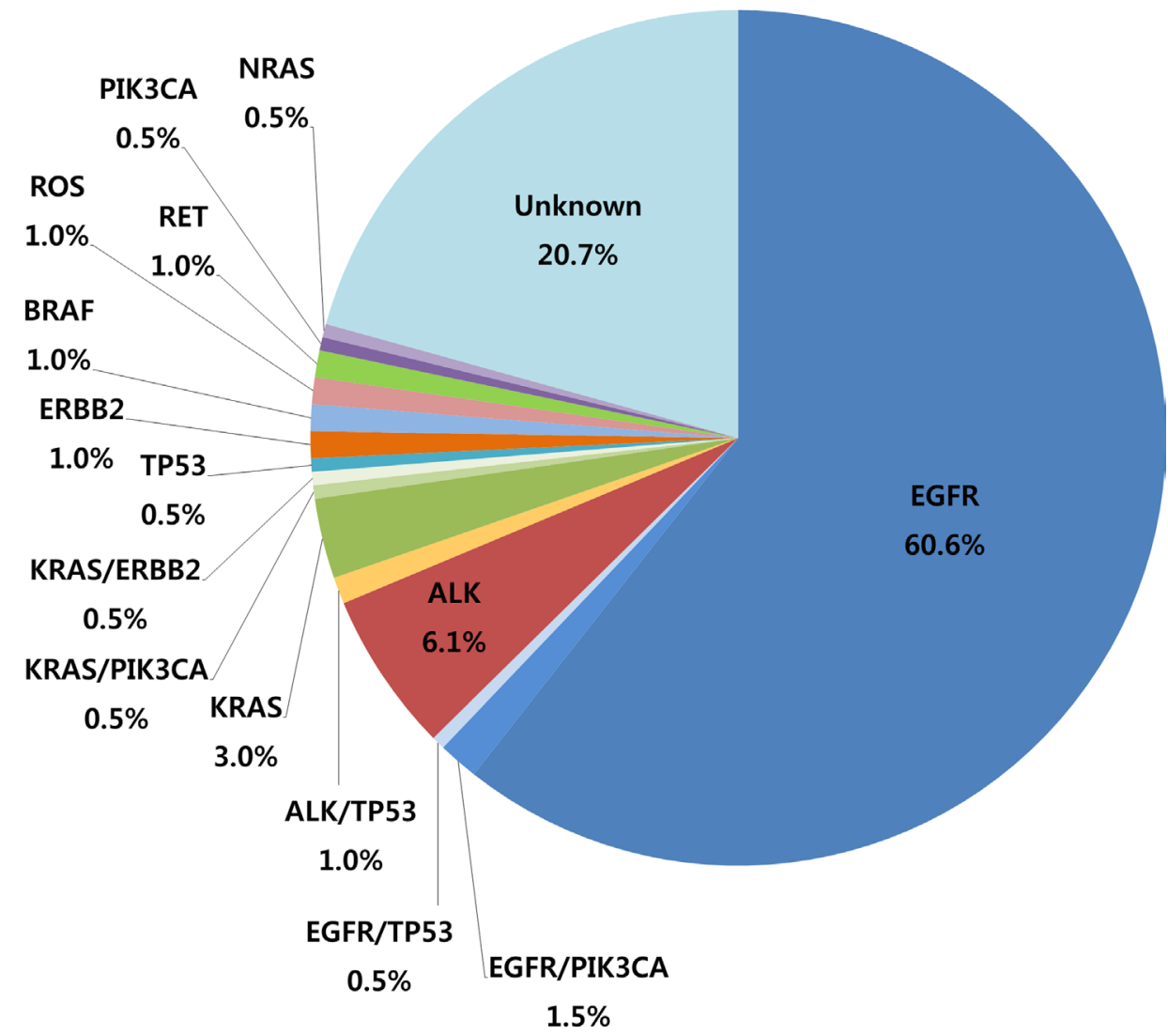

Figure 2: Frequency of driver gene mutations in lung adenocarcinomas from East Asian never-smoker females.

EGFR mutations were associated frequently with lepidic and acinar patterns and infrequently with mucinous patterns in cases where the histologic pattern predominated in $>10 \%$ of the tumor area. $A L K$ rearrangement was more frequently detected in tumors with solid and mucinous patterns, while $K R A S$ mutations were also commonly found in tumors with a mucinous pattern. Other mutations were not associated with histologic subtypes (Supplemental Table 3).

Patients with tumors harboring EGFR and $B R A F$ mutations were older than those with wild-type tumors, whereas $A L K$ gene fusions and $E R B B 2$ mutations were 
Table 2: Relationship between driver mutation status and histologic subclassification of adenocarcinoma according to predominant type

\begin{tabular}{|c|c|c|c|c|c|c|c|c|}
\hline & Total & Lepidic $^{1}$ & Acinar $^{2}$ & Papillary & Micropapillary & Solid & Mucinous $^{3}$ & $p$-value \\
\hline n (\%) & $198(100)$ & $11(5.6)$ & $142(71.7)$ & $18(9.1)$ & $1(0.5)$ & $17(8.6)$ & $9(4.5)$ & \\
\hline Wild-type & $41(20.7)$ & $3(7.3)$ & $29(70.7)$ & $2(4.9)$ & $0(0)$ & $3(7.3)$ & $4(9.8)$ & $\begin{array}{l}0.446 \\
\text { Mucinous } \\
\text { vs. others: } \\
0.090\end{array}$ \\
\hline Mutant type & $157(79.3)$ & $8(5.1)$ & $113(72.0)$ & $16(10.2)$ & $1(0.6)$ & $14(8.9)$ & $5(3.2)$ & \\
\hline EGFR & $124(62.6)$ & $7(5.6)$ & $102(82.3)$ & $9(7.3)$ & $1(0.8)$ & $5(4.0)$ & $0(0)$ & $<0.001$ \\
\hline ALK & $14(7.1)$ & $0(0)$ & $6(42.9)$ & $2(14.3)$ & $0(0)$ & $5(35.7)$ & $1(7.1)$ & 0.012 \\
\hline KRAS & $8(4.0)$ & $1(12.5)$ & $1(12.5)$ & $0(0)$ & $0(0)$ & $2(25.0)$ & $4(50.0)$ & $<0.001$ \\
\hline PIK3CA & $5(2.5)$ & $0(0)$ & $3(60.0)$ & $1(20.0)$ & $0(0)$ & $0(0)$ & $1(20.0)$ & 0.31 \\
\hline TP53 & $4(2.0)$ & $0(0)$ & $4(2.8)$ & $0(0)$ & $0(0)$ & $0(0)$ & $0(0)$ & 1 \\
\hline ERBB2 & $3(1.5)$ & $0(0)$ & $2(66.7)$ & $0(0)$ & $0(0)$ & $0(0)$ & $1(33.3)$ & 0.272 \\
\hline BRAF & $2(1.0)$ & $0(0)$ & $0(0)$ & $2(100)$ & $0(0)$ & $0(0)$ & $0(0)$ & 0.043 \\
\hline ROS1 & $2(1.0)$ & $0(0)$ & $0(0)$ & $1(50.0)$ & $0(0)$ & $1(50.0)$ & $0(0)$ & 0.086 \\
\hline RET & $2(1.0)$ & $0(0)$ & $1(50.0)$ & $1(50.0)$ & $0(0)$ & $0(0)$ & $0(0)$ & 0.487 \\
\hline NRAS & $1(0.5)$ & $0(0)$ & $0(0)$ & $0(0)$ & $0(0)$ & $1(100)$ & $0(0)$ & 0.192 \\
\hline
\end{tabular}

${ }^{1}$ Two cases of minimally invasive adenocarcinoma were included in the lepidic predominant type.

${ }^{2} \mathrm{Six}$ cases with acinar pattern showed concurrent mutation of EGFR/PIK3CA $(n=3), \operatorname{EGFR/TP53}(n=1)$, and ALK/TP53 $(n=2)$.

${ }^{3}$ Two cases of mucinous adenocarcinoma showed concurrent mutation of $\operatorname{KRAS/PIK3CA}(n=1)$ and $K R A S / E R B B 2(n=1)$.

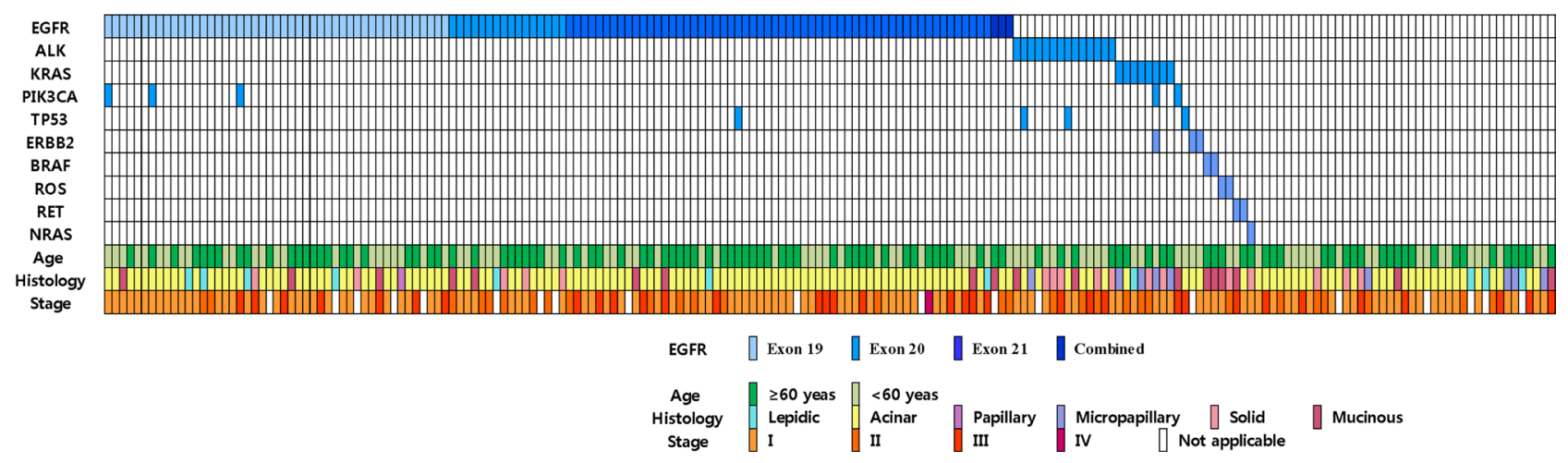

Figure 3: Diagram demonstrating driver gene mutation status and clinicopathologic features in 198 adenocarcinomas from East Asian never-smoker females. Most mutations were mutually exclusive with the rare exception of concurrent mutation of EGFR/PIK3CA $(n=3), E G F R / T P 53(n=1), A L K / T P 53(n=2), K R A S / P I K 3 C A(n=1)$, and KRAS/ERBB2 $(n=1)$. Patients who received concurrent chemoradiation therapy and those who did not undergo lymph node dissection were excluded in the analysis of TNM stage.

associated with younger age at diagnosis (Supplemental Table 4). Driver gene mutation status was not associated with tumor stage.

\section{DISCUSSION}

In this study, we evaluated the status of driver gene mutations in lung adenocarcinoma samples from 198 East
Asian female never-smokers using the MassARRAY ${ }^{\circledR}$ LungCarta Panel and $A L K, R O S 1$, and RET fusion assays. Approximately $79 \%$ of patients harbored driver gene mutations, and EGFR mutation (63\%) was the most frequent driver mutation detected. Other genetic alterations occurred less frequently with $A L K$ gene fusion, KRAS mutation, ERBB 2 mutation, HER2 mutation, ROS1 rearrangement, and $R E T$ rearrangement occurring in $7 \%$, 
A

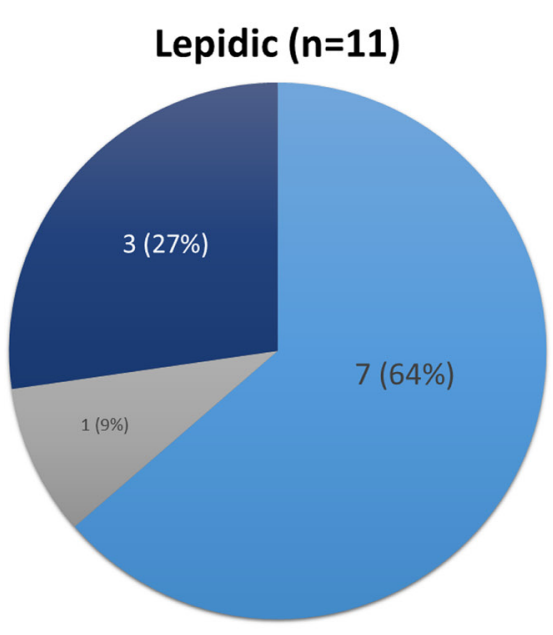

C

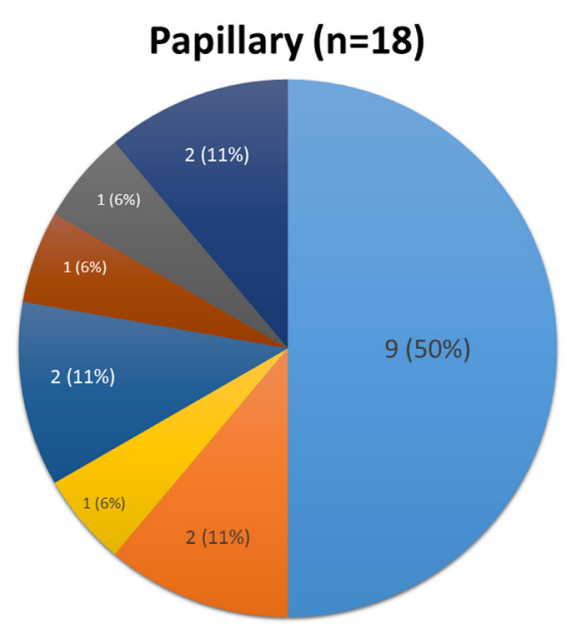

E

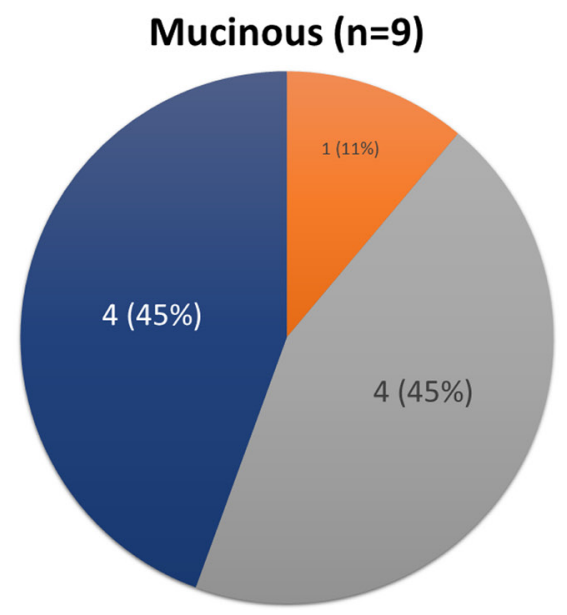

B

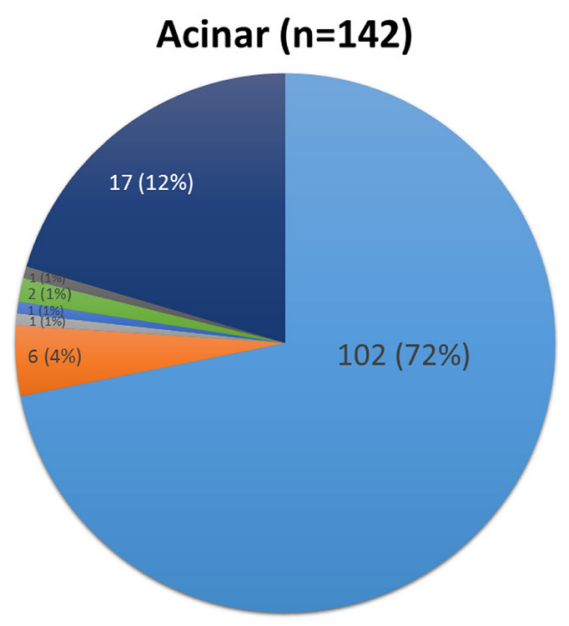

D

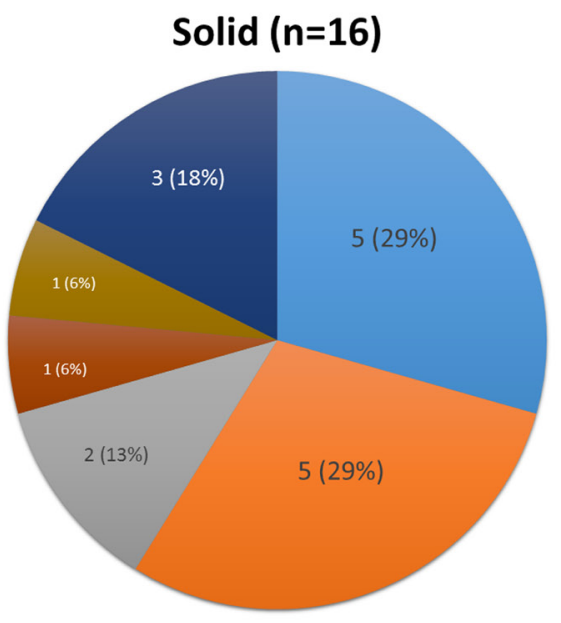

EGFR

ALK

KRAS

PIK3CA

TP53

ERBB2

- BRAF

ROS1

RET

NRAS

- Wild

Figure 4: Frequency of driver gene mutations according to predominant histologic subtype. (A) Lepidic, (B) Acinar, (C) Papillary, (D) Solid, (E) Mucinous subtype. In acinar subtype, four cases with concurrent mutations of EGFR/PIK3CA $(n=3)$ and EGFR/TP53 $(n=1)$ are represented as an EGFR mutation, and 2 cases of ALK/TP53 mutation as an ALK mutation. In mucinous subtype, two cases with concurrent mutations of KRAS/PIK3CA and KRAS/ERBB2 are represented as a KRAS mutation. 
$4 \%, 1.5 \%, 1 \%, 1 \%$, and $1 \%$ of cases, respectively. Most mutations were mutually exclusive.

Ethnic background is a well-established factor in NSCLC. Asian female non-smokers were the specific epidemiologic subgroup in this study, and a few previous large-scale studies have shown that Asian ethnicity is a prognostic factor of overall survival for NSCLC patients [15-17]. The link between ethnicity and cancer survival rates is likely due to differences in genetic background among ethnicities. Compared to Caucasians, East Asians with NSCLC have higher rates of EGFR mutations and lower rates of $K R A S$ and $L K B 1$ mutations [18]. According to a recent meta-analysis of 94 studies, the rate of EGFR mutation in lung adenocarcinoma in Asians $(47.9 \%)$ is higher than that in Westerners $(19.2 \%)$, while KRAS $(11.2 \%)$ and LKB1 (4.0\%) mutation rates are lower in Asians than in Westerners (26.1\% and 16.2\%, respectively) [19]. Smoking status is also an important factor in the development of lung adenocarcinoma. Lung cancers in never-smokers are more frequently associated with adenocarcinoma with EGFR mutations and less frequently with $K R A S$ mutations [20]. In a recent study of lung adenocarcinomas, mutation rates for EGFR (39\%), KRAS (4\%), ALK (15\%), and HER2 (5\%) in never-smoker groups differed from rates in current or former smoker groups $(10 \%, 35 \%, 4 \%$, and $1 \%$, respectively) [21]. Notably, the proportion of female lung cancers in neversmokers is much higher in East Asia than in Europe or the United States (60\% vs 15-20\%) [20].

Although many studies have investigated driver gene mutations in lung adenocarcinoma, only a few have focused specifically on Asian female never-smokers despite the demonstrated importance of this patient group for selection of targeted candidates for NSCLC therapy [22-24]. Zhang et al. analyzed EGFR, KRAS, ALK, HER2, and $B R A F$ mutation in 349 Chinese never-smoker females with lung adenocarcinoma and discovered mutation rates of $76 \%, 5 \%, 4 \%, 2 \%$, and $1 \%$ for $E G F R, H E R 2, A L K$, $K R A S$, and $H E R 2$, respectively, while only $12 \%$ of cases harbored no detected mutation [25]. In an analysis of mutations of 10 driver genes (EGFR, KRAS, NRAS, HRAS, HER2, BRAF, ALK, PIK3CA, TP53, and LKB1) in 52 lung adenocarcinomas from East Asian never-smokers including 41 women [26], Sun et al. found similar rates of genetic alterations: $E G F R$ mutation in $79 \%$ of cases, EML4-ALK fusion in 6\% of cases, HER 2 mutation in $4 \%$ of cases, and $K R A S$ mutation in $2 \%$ of cases. In addition, only $10 \%$ of patients did not harbor any detected mutation in these genes. Ren et al. reported EGFR mutation in 70\% and $A L K$ rearrangement in $9.6 \%$ in adenocarcinomas from never-smoker Chinese women (see Supplemental Table 5 for summary of these studies) [27]. The incidences of mutation detected in this study are consistent with those of previous studies.

Several important features distinguish our study from previous studies. In our study, we analyzed a total of
26 known oncogenes and 3 fusion genes. We discovered that $1 \%$ of lung adenocarcinomas from East Asian neversmoker female patients harbored gene rearrangements of ROS1 and RET, which have recently been recognized as driver genes in lung adenocarcinoma [28-30] but had not been evaluated in East Asian female never-smokers. We used a multiplex method that can be used in routine clinical practice and our results demonstrated that this method was comparable to traditional mutational analysis using polymerase chain reaction (PCR) for each gene. The use of a multiplexed PCR-based assay to genotype NSCLCs was recently demonstrated to be clinically feasible [31]. Moreover, we confirmed well-known associations of driver gene mutations with histologic subtypes and clinical characteristics. EGFR mutation correlated positively with older age and a predominantly acinar pattern [25, 32, 33], while $A L K$ rearrangement was associated with younger age and solid histology [34, 35]. KRAS mutation was detected more frequently in mucinous adenocarcinoma $[25,36]$. Furthermore, most PIK3CA mutations coexisted with other mutations [26]. The fact that our findings are consistent with those of previous studies supports the value of the multiplex method in mutation analysis and suggests that clinicopathologic associations are useful for determination of the priority of driver mutation tests.

The most outstanding result of our study was that driver gene mutations were detected in $79 \%$ of female never-smoker Asian patients. Targeted therapies for EGFR (erlotinib/gefitinib) and $A L K$ (crizotinib) are currently available, and $70 \%$ of female never-smoker Asian patients with EGFR mutation (63\%) or $A L K$ rearrangement $(7 \%)$ may benefit from such targeted therapies. An additional $10 \%$ of patients in our study may benefit from newly developed targeted drugs. A recent clinical trial described a partial response to the $E G F R / H E R 2$ inhibitor BIBW2922 in a HER2 mutant tumor [37], suggesting that this new drug is a promising treatment strategy. More comprehensive genomic analysis and deep sequencing may be necessary to identify genetic alterations in the remaining $20 \%$ of patients with no known mutations [26]. Notably, known driver gene mutations were found less frequently in mucinous adenocarcinoma in our study, suggesting the possibility of mutation in another driver gene in this histologic subtype.

In conclusion, lung cancer in never-smoker Asian females is a distinct entity, with the majority of these lung cancers developing from oncogenic mutations.

\section{METHODS}

\section{Study population}

Specimens were obtained from Samsung Medical Center (SMC) in Seoul, Korea with prior informed patient consent and approval by the Institutional Review Board of Samsung Medical Center. Between January 2008 
and January 2013, 3796 consecutive patients underwent pulmonary resection with curative intent for primary lung cancer at our institute.

After excluding 1307 patients with nonadenocarcinoma (Figure 1A), the remaining 2489 patients consisted of 1302 men and 1187 women (Figure 1B). Of the 1187 female patients with lung adenocarcinoma, 422 patients were excluded due to a lack of smoking information. Of the remaining 765 female patients, 94.9\% (726 women) were never-smokers (Figure 1C). Among the 726 never-smoker female pulmonary adenocarcinoma cases, 198 had sufficient tissue for genomic analysis and were included in this study.

\section{Data collection and histologic classification of adenocarcinoma}

Study data were abstracted from in-hospital charts and electronic medical records by trained experienced nurses from the Departments of Medical Oncology, Surgical Oncology, Laboratory Medicine, Pathology, and Nursing at Samsung Medical Center. Baseline clinical characteristics included gender, age at diagnosis, smoking history, alcohol consumption status, date of diagnosis of advanced lung cancer, tumor histology, tumor stage, and ambulatory status at diagnostic work-up. Tumor stage was defined according to the seventh edition of the American Joint Committee on Cancer [38]. Smoking history and alcohol consumption status were determined by self-reported answers on questionnaires. Never-smokers were defined as patients who smoked less than 100 cigarettes over their lifetime. Histologic classification was determined according to the International Association for the Study of Lung Cancer, American Thoracic Society, and European Respiratory Society classification of lung adenocarcinomas [39]. All histologic patterns that covered at least $10 \%$ of the tumor area were recorded, and the predominant pattern was defined as the pattern that covered the largest portion of the tumor area.

\section{DNA and RNA extraction}

Genomic DNA or RNA was extracted from lung tumors or distant histologically normal lung tissue using standard protocols (RNeasy Mini Kit and QIAamp DNA Mini Kit, Qiagen, Valencia, CA, USA).

\section{ALK, ROS1, and RET fusion assays}

The nCounter ${ }^{\mathrm{TM}}$ gene expression assays were customdesigned and synthesized by NanoString Technologies (Seattle, WA, USA). Hybridization, sample cleanup, and digital reporter counts were performed according to the manufacturer's protocol. RNA was obtained from freshfrozen tissues using the Qiagen RNeasy Mini Kit (Qiagen, Valencia, CA, USA). RNA concentration was assessed by spectrophotometry using the Nanodrop 8000 (ThermoScientific, Wilmington, DE, USA).
Samples were processed according to the gene expression protocol of NanoString Technologies. Briefly, total RNA was hybridized to a multiplexed mixture of custom-designed nCounter ${ }^{\mathrm{TM}}$ capture and reporter probes complementary to $A L K, R O S 1$, and RET target sequences (Supplemental Table 2) for at least $16 \mathrm{~h}$ at $65^{\circ} \mathrm{C}$. The samples were cleaned up and processed using an automated nCounter ${ }^{\mathrm{TM}}$ Sample Prep Station (NanoString Technologies). Unhybridized probes were removed, and the hybridization complex was immobilized onto a cartridge and aligned. Fluorescently labeled, color-coded reporters were subsequently imaged on an nCounter ${ }^{\mathrm{TM}}$ Digital Analyzer (NanoString Technologies) set at 1155 fields of view. Raw reporter counts were collected using nSolver software v1.0 (NanoString Technologies).

\section{LungCarta analysis}

High-throughput multiplex mutation profiling was performed using the MassARRAY ${ }^{\circledR}$ LungCarta Panel Version 1.0 (Sequenom, San Diego, CA, USA). This panel permits screening of 214 mutations across 26 oncogenes and tumor suppressors with a limit of sensitivity of approximately $10 \%$ with the use of 480 ng DNA [17]. DNA was amplified using the OncoCarta PCR primer mix, unincorporated nucleotides were inactivated by shrimp alkaline phosphatase, and a single base extension reaction was performed using extension primers that hybridize adjacent to the mutation. Multiplexed reactions were spotted onto the SpectroChipII (Sequenom) using the MassARRAY Nanodispenser. Peaks with different mass were resolved by matrix-assisted laser desorption/ ionization time-of-flight on the MassARRAY Compact Analyzer. A predefined ratio of expected normal allele to mutant allele at a specific nucleotide position allows mutations to be detected using primer extensions at that specific position. Because of the multiplexing capabilities of this assay, multiple mutations are detected simultaneously using one panel. Further details of the multiplex methodology can be found in the protocol provided by the manufacturer.

\section{Sanger sequencing}

To validate the LungCarta analysis, we performed Sanger sequencing of EGFR in 11 selected cases (4 cases of EGFR E746_A750del, 4 cases of EGFR L858R, and 3 cases of KRAS G12D) according to the method described previously by our group [40].

\section{Statistical analysis}

Pearson's chi-squared, Fisher's exact, and independent $t$ tests were used as indicated. All tests were two sided, and a $p$-value of $<0.05$ was considered statistically significant. Statistical analyses were performed using SPSS software (SPSS Inc., Chicago, IL, USA). 


\section{ACKNOWLEDGMENTS}

This study was supported by the Converging Research Center Program (No. 2013K000278) funded by the Korean government (The Ministry of Science, Information and Communications Technology, and Future Planning) and by the R\&D Program for the Society of the National Research Foundation (NRF) funded by the Ministry of Science, ICT, and Future Planning (NRF2013M3C8A1078501) and by a grant of the Korea Health Technology R\&D Project through the Korea Health Industry Development Institute(KHIDI), funded by the Ministry of Health \& Welfare, Republic of Korea (grant number:HI13C2096).

\section{REFERENCES}

1. Jemal A, Bray F, Center MM, Ferlay J, Ward E, Forman D. Global cancer statistics. CA Cancer J Clin. 2011; 61:69-90.

2. Ferlay J, Shin HR, Bray F, Forman D, Mathers C, Parkin DM. Estimates of worldwide burden of cancer in 2008: GLOBOCAN 2008. International journal of cancer Journal international du cancer. 2010; 127:2893-2917.

3. Siegel R, Ward E, Brawley O, Jemal A. Cancer statistics, the impact of eliminating socioeconomic and racial disparities on premature cancer deaths. CA Cancer J Clin. 2011; 61:212-236.

4. Scagliotti GV, Longo M, Novello S. Nonsmall cell lung cancer in never smokers. Current opinion in oncology. 2009; 21:99-104.

5. Toh CK, Wong EH, Lim WT, Leong SS, Fong KW, Wee J, Tan EH. The impact of smoking status on the behavior and survival outcome of patients with advanced non-small cell lung cancer: a retrospective analysis. Chest. 2004; 126:1750-1756.

6. Thatcher N, Chang A, Parikh P, Rodrigues Pereira J, Ciuleanu $\mathrm{T}$, von Pawel J, Thongprasert S, Tan EH, Pemberton K, Archer V, Carroll K. Gefitinib plus best supportive care in previously treated patients with refractory advanced non-small-cell lung cancer: results from a randomised, placebo-controlled, multicentre study (Iressa Survival Evaluation in Lung Cancer). Lancet. 2005; 366:1527-1537.

7. Mok TS, Wu YL, Thongprasert S, Yang CH, Chu DT, Saijo N, Sunpaweravong P, Han B, Margono B, Ichinose Y, Nishiwaki Y, Ohe Y, Yang JJ, et al. Gefitinib or carboplatin-paclitaxel in pulmonary adenocarcinoma. The New England journal of medicine. 2009; 361:947-957.

8. Maemondo M, Inoue A, Kobayashi K, Sugawara S, Oizumi S, Isobe H, Gemma A, Harada M, Yoshizawa H, Kinoshita I, Fujita Y, Okinaga S, Hirano H, et al. Gefitinib or chemotherapy for non-small-cell lung cancer with mutated EGFR. The New England journal of medicine. $2010 ; 362: 2380-2388$.
9. Soda M, Choi YL, Enomoto M, Takada S, Yamashita Y, Ishikawa S, Fujiwara S, Watanabe $\mathrm{H}$, Kurashina $\mathrm{K}$, Hatanaka H, Bando M, Ohno S, Ishikawa $\mathrm{Y}$, et al. Identification of the transforming EML4-ALK fusion gene in non-small-cell lung cancer. Nature. 2007; 448:561-566.

10. Takahashi T, Sonobe M, Kobayashi M, Yoshizawa A, Menju T, Nakayama E, Mino $\mathrm{N}$, Iwakiri $\mathrm{S}$, Sato K, Miyahara R, Okubo K, Manabe T, Date H. Clinicopathologic features of non-small-cell lung cancer with EML4-ALK fusion gene. Annals of surgical oncology. 2010; 17:889-897.

11. Solomon B, Varella-Garcia M, Camidge DR. ALK gene rearrangements: a new therapeutic target in a molecularly defined subset of non-small cell lung cancer. Journal of thoracic oncology: official publication of the International Association for the Study of Lung Cancer. 2009; 4:1450-1454.

12. Chen Z, Sasaki T, Tan X, Carretero J, Shimamura T, Li D, Xu C, Wang Y, Adelmant GO, Capelletti M, Lee HJ, Rodig SJ, Borgman C, et al. Inhibition of ALK, PI3K/ MEK, and HSP90 in murine lung adenocarcinoma induced by EML4-ALK fusion oncogene. Cancer research. 2010; 70:9827-9836.

13. Zhang X, Zhang S, Yang X, Yang J, Zhou Q, Yin L, An S, Lin J, Chen S, Xie Z, Zhu M, Wu YL. Fusion of EML4 and ALK is associated with development of lung adenocarcinomas lacking EGFR and KRAS mutations and is correlated with ALK expression. Mol Cancer. 2010; 9:188.

14. Shaw AT, Yeap BY, Mino-Kenudson M, Digumarthy SR, Costa DB, Heist RS, Solomon B, Stubbs H, Admane S, McDermott U, Settleman J, Kobayashi S, Mark EJ, et al. Clinical features and outcome of patients with non-smallcell lung cancer who harbor EML4-ALK. Journal of clinical oncology: official journal of the American Society of Clinical Oncology. 2009; 27:4247-4253.

15. Ou SH, Ziogas A, Zell JA. Asian ethnicity is a favorable prognostic factor for overall survival in non-small cell lung cancer (NSCLC) and is independent of smoking status. J Thorac Oncol. 2009; 4:1083-1093.

16. Ahn MJ, Lee J, Park YH, Ahn JS, Ziogas A, Zell JA, Park K, Ou SH. Korean ethnicity as compared with white ethnicity is an independent favorable prognostic factor for overall survival in non-small cell lung cancer before and after the oral epidermal growth factor receptor tyrosine kinase inhibitor era. J Thorac Oncol. 2010; 5:1185-1196.

17. Kawaguchi T, Matsumura A, Fukai S, Tamura A, Saito R, Zell JA, Maruyama Y, Ziogas A, Kawahara M, Ignatius Ou SH. Japanese ethnicity compared with Caucasian ethnicity and never-smoking status are independent favorable prognostic factors for overall survival in non-small cell lung cancer: a collaborative epidemiologic study of the National Hospital Organization Study Group for Lung Cancer (NHSGLC) in Japan and a Southern California Regional Cancer Registry databases. J Thorac Oncol. 2010; 5:1001-1010. 
18. El-Telbany A, Ma PC. Cancer genes in lung cancer: racial disparities: are there any? Genes Cancer. 2012; 3:467-480.

19. Dearden S, Stevens J, Wu YL, Blowers D. Mutation incidence and coincidence in non small-cell lung cancer: metaanalyses by ethnicity and histology (mutMap). Ann Oncol. 2013; 24:2371-2376.

20. Sun S, Schiller JH, Gazdar AF. Lung cancer in never smokers-a different disease. Nat Rev Cancer. 2007; 7:778-790.

21. Kris MG, Johnson BE, Berry LD, Kwiatkowski DJ, Iafrate AJ, Wistuba II, Varella-Garcia M, Franklin WA, Aronson SL, Su PF, Shyr Y, Camidge DR, Sequist LV, et al. Using multiplexed assays of oncogenic drivers in lung cancers to select targeted drugs. JAMA. 2014; 311:1998-2006.

22. Fukuoka M, Yano S, Giaccone G, Tamura T, Nakagawa K, Douillard JY, Nishiwaki Y, Vansteenkiste J, Kudoh S, Rischin D, Eek R, Horai T, Noda K, et al. Multi-institutional randomized phase II trial of gefitinib for previously treated patients with advanced non-small-cell lung cancer (The IDEAL 1 Trial). J Clin Oncol. 2003; 21:2237-2246.

23. Miller VA, Kris MG, Shah N, Patel J, Azzoli C, Gomez J, Krug LM, Pao W, Rizvi N, Pizzo B, Tyson L, Venkatraman E, Ben-Porat L, et al. Bronchioloalveolar pathologic subtype and smoking history predict sensitivity to gefitinib in advanced non-small-cell lung cancer. J Clin Oncol. 2004; 22:1103-1109.

24. Mitsudomi T, Morita S, Yatabe Y, Negoro S, Okamoto I, Tsurutani J, Seto T, Satouchi M, Tada H, Hirashima T, Asami K, Katakami N, Takada M, et al. Gefitinib versus cisplatin plus docetaxel in patients with non-small-cell lung cancer harbouring mutations of the epidermal growth factor receptor (WJTOG3405): an open label, randomised phase 3 trial. Lancet Oncol. 2010; 11:121-128.

25. Zhang Y, Sun Y, Pan Y, Li C, Shen L, Li Y, Luo X, Ye T, Wang R, Hu H, Li H, Wang L, Pao W, et al. Frequency of driver mutations in lung adenocarcinoma from female never-smokers varies with histologic subtypes and age at diagnosis. Clin Cancer Res. 2012; 18:1947-1953.

26. Sun Y, Ren Y, Fang Z, Li C, Fang R, Gao B, Han X, Tian W, Pao W, Chen H, Ji H. Lung adenocarcinoma from East Asian never-smokers is a disease largely defined by targetable oncogenic mutant kinases. J Clin Oncol. 2010; 28:4616-4620.

27. Ren S, Chen X, Kuang P, Zheng L, Su C, Li J, Li B, Wang Y, Liu L, Hu Q, Zhang J, Tang L, Li X, et al. Association of EGFR mutation or ALK rearrangement with expression of DNA repair and synthesis genes in neversmoker women with pulmonary adenocarcinoma. Cancer. 2012; 118:5588-5594.

28. Kohno T, Ichikawa H, Totoki Y, Yasuda K, Hiramoto M, Nammo T, Sakamoto H, Tsuta K, Furuta K, Shimada Y, Iwakawa R, Ogiwara H, Oike T, et al. KIF5B-RET fusions in lung adenocarcinoma. Nat Med. 2012; 18:375-377.

29. Ju YS, Lee WC, Shin JY, Lee S, Bleazard T, Won JK, Kim YT, Kim JI, Kang JH, Seo JS. A transforming KIF5B and RET gene fusion in lung adenocarcinoma revealed from whole-genome and transcriptome sequencing. Genome Res. 2012; 22:436-445.

30. Bergethon K, Shaw AT, Ou SH, Katayama R, Lovly CM, McDonald NT, Massion PP, Siwak-Tapp C, Gonzalez A, Fang R, Mark EJ, Batten JM, Chen H, et al. ROS1 rearrangements define a unique molecular class of lung cancers. J Clin Oncol. 2012; 30:863-870.

31. Sequist LV, Heist RS, Shaw AT, Fidias P, Rosovsky R, Temel JS, Lennes IT, Digumarthy S, Waltman BA, Bast E, Tammireddy S, Morrissey L, Muzikansky A, et al. Implementing multiplexed genotyping of nonsmall-cell lung cancers into routine clinical practice. Ann Oncol. 2011; 22:2616-2624.

32. Choi YH, Lee JK, Kang HJ, Lee TS, Kim HR, Kim CH, Koh JS, Baek HJ, Lee JC, Na II. Association between age at diagnosis and the presence of EGFR mutations in female patients with resected non-small cell lung cancer. J Thorac Oncol. 2010; 5:1949-1952.

33. Li C, Fang R, Sun Y, Han X, Li F, Gao B, Iafrate AJ, Liu XY, Pao W, Chen H, Ji H. Spectrum of oncogenic driver mutations in lung adenocarcinomas from East Asian never smokers. PLoS One. 2011; 6:e28204.

34. Sun JM, Lira M, Pandya K, Choi YL, Ahn JS, Mao M, Han J, Park K, Ahn MJ, Kim J. Clinical characteristics associated with ALK rearrangements in never-smokers with pulmonary adenocarcinoma. Lung Cancer. 2014; 83:259-264.

35. Rodig SJ, Mino-Kenudson M, Dacic S, Yeap BY, Shaw A, Barletta JA, Stubbs H, Law K, Lindeman N, Mark E, Janne PA, Lynch T, Johnson BE, et al. Unique clinicopathologic features characterize ALK-rearranged lung adenocarcinoma in the western population. Clin Cancer Res. 2009; 15:5216-5223.

36. Rekhtman N, Ang DC, Riely GJ, Ladanyi M, Moreira AL. KRAS mutations are associated with solid growth pattern and tumor-infiltrating leukocytes in lung adenocarcinoma. Mod Pathol. 2013; 26:1307-1319.

37. De Greve J, Teugels E, Geers C, Decoster L, Galdermans D, De Mey J, Everaert H, Umelo I, In't Veld P, Schallier D. Clinical activity of afatinib (BIBW 2992) in patients with lung adenocarcinoma with mutations in the kinase domain of HER2/neu. Lung Cancer. 2012; 76:123-127.

38. Tanoue LT, Detterbeck FC. New TNM classification for non-small-cell lung cancer. Expert Rev Anticancer Ther. 2009; 9:413-423.

39. Travis WD, Brambilla E, Noguchi M, Nicholson AG, Geisinger KR, Yatabe Y, Beer DG, Powell CA, Riely GJ, Van Schil PE, Garg K, Austin JH, Asamura H, et al. International association for the study of lung cancer/ american thoracic society/european respiratory society international multidisciplinary classification of lung adenocarcinoma. J Thorac Oncol. 2011; 6:244-285.

40. Ha SY, Han J, Lee JJ, Kim YE, Choi Y-L, Kim HK. Mucoepidermoid Carcinoma of Tracheobronchial Tree: Clinicopathological Study of 31 Cases. The Korean Journal of Pathology. 2011; 45:175-181. 